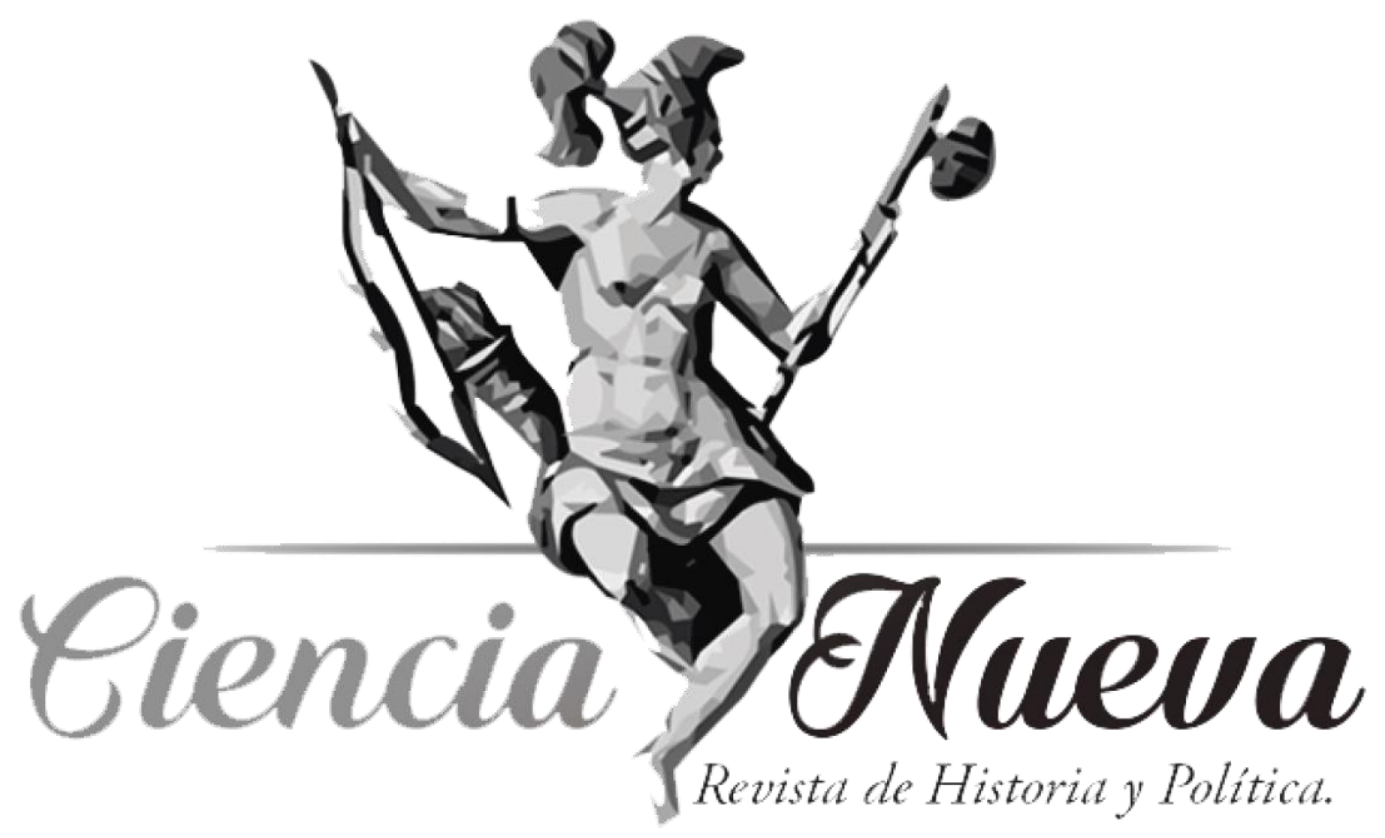

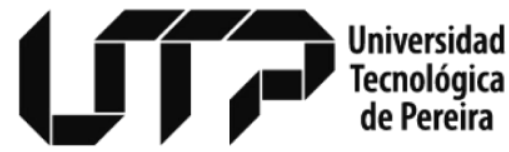

Maestría en Historia

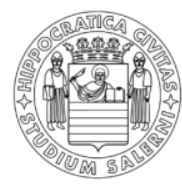

UNIVERSITÀ DEGLI STUDI DI SALERNO

\title{
EDITORIAL
}

\section{OPOSICIÓN POLÍTICA EN LA NUEVA GRANADA: UN ANÁLISIS DE LA CONFRONTACIÓN ENTRE LOS PERIÓDICOS LA BANDERA NACIONAL Y EL ARGOS (1837-1839) POLITICAL OPPOSITION IN THE NUEVA GRANADA: AN ANALYSIS OF THE CONFRONTATION BETWEEN THE NEWSPAPERS LA BANDERA NACIONAL AND EL ARGOS (1837-1839)}

Jhon Jaime Correa Ramírez pp. $02-21$

Vol. 2 Núm. 1, Enero-Junio de 2018 Pereira, Colombia 


\title{
OPOSICIÓN POLÍTICA EN LA NUEVA GRANADA: UN ANÁLISIS DE LA CONFRONTACIÓN ENTRE LOS PERIÓDICOS LA BANDERA NACIONAL Y EL ARGOS (1837-1839)* \\ POLITICAL OPPOSITION IN THE NUEVA GRANADA: AN ANALYSIS OF THE CONFRONTATION BETWEEN THE NEWSPAPERS LA BANDERA NACIONAL AND EL ARGOS (1837-1839)
}

\author{
John Jaime Correa Ramírez ${ }^{* *}$ \\ jjcorrea@utp.edu.co \\ ORCID: https://orcid.org/0000-0002-1741-6534
}

\begin{aligned} & \hline Recibido: 26 de septiembre de 2017 \\ & Revisado: 01 de noviembre de 2017 \\ & Aceptado: 01 de diciembre de 2017 \\ & Publicado: 12 de marzo de 2018 \\ & \hline\end{aligned}

\section{Introducción.}

$7 \mathrm{n}$ el ambiente político de los primeros años de la vida republicana en Colombia, la guerra de periódicos y folletos fue un elemento muy característico de la cultura política que dio lugar a la exacerbación de pasiones de diversa índole. Muchos fueron los resentimientos y los odios que se engendraron en medio de acusaciones, provocaciones, estigmatizaciones, dicterios, injurias y agravios, que iban polarizando la naciente opinión pública.

El objetivo fundamental de la presente ponencia es realizar una caracterización de la oposición política en Colombia entre los años 1837 y 1839, la cual sirvió de antesala a la radicalización de las facciones partidistas que posteriormente darían lugar a la génesis de los dos partidos políticos más tradicionales en la historia del país, a saber, el liberalismo y el conservatismo.

Para entender la coyuntura política de estos dos años seguiremos el rastro de dos periódicos en la capital Santafé de Bogotá: La Bandera Nacional y El Argos, que sirvieron de voceros, el primero, a los miembros de la oposición liderados por el presidente saliente y héroe de la independencia, General Francisco de Paula Santander; y el segundo, a los defensores del gobierno. A pesar de que aún no se puede hablar para esta época con propiedad de identidades políticas definidas, si es posible señalar algunos rasgos identitarios promovidos a través de las acusaciones que se lanzaban mutuamente los publicistas de ambos periódicos. Los editores de La Bandera Nacional se identificaban como liberales progresistas

\footnotetext{
* El presente artículo respeta las directrices y normas dispuestas en la Declaración de Ética de Publicación de Ciencia Nueva, Revista de Historia y Política. Esta declaración puede consultarse en la página web de la revista: revistas.utp.edu.co/index.php/historia

** Historiador de la Universidad Nacional de Colombia sede Medellín, Especialista en Gestión y Promoción Cultural y Magíster en Ciencia Política de la Universidad de Antioquia, y Doctor en Ciencias de la Educación de la Universidad Tecnológica de Pereira-RUDECOLOMBIA. Docente titular de la Escuela de Ciencias Sociales y Director de la Maestría en Historia de la Universidad Tecnológica de Pereira, y co-director del Grupo interinstitucional de Investigación UIS-UTP "Políticas, Sociabilidades y Representaciones HistóricoEducativas (PSORHE)", clasificado de categoría A1 ante Colciencias.
} 
y acusaban a los defensores del gobierno de "ministeriales", "serviles", "godos" y "retrógrados". Los de El Argos se publicitaban como moderados, republicanos y liberales, y de paso, señalaban a los opositores como "facciosos", "subversivos" y "antipatriotas", que entorpecían el camino hacia la anhelada unidad nacional.

En este juego de imágenes y contraimágenes estereotipadas, en el que, según Fernán González, "el contrario queda necesariamente desprovisto de toda legitimidad y la confrontación será de estilo maniqueo, como lucha entre el bien y el mal absolutos", se centran los referentes de análisis sobre los que haré referencia a continuación. Estos aspectos connotan, en términos de cultura política, un modo particular de intolerancia hacia el disenso y la alteridad política, pero sobre todo demuestran el rol sectario y beligerante de los medios de comunicación en el proceso de formación pedagógica de la opinión pública en nuestro país. Incluso se podría decir que la pluma ha sido un instrumento tan eficaz en la política colombiana como también lo han sido las armas. Sin desconocer el valor formativo que la prensa pudo tener en la difusión de ideas políticas entre los grupos letrados de la sociedad, no cabe duda que también contribuyó a retroalimentar los sentimientos sectarios característicos de la política en Colombia.

\section{Algunos elementos del contexto histórico: la oposición al gobierno de Santander (1832-1837)}

Para poder entender con mayor precisión los debates llevados a cabo entre los periódicos La Bandera Nacional y El Argos es menester dar cuenta de los acontecimientos históricos que antecedieron al año de 1837, en el que José Vicente Márquez asumió la presidencia de la república, en medio de la oposición liderada por el presidente saliente, General Santander.

En el proceso de construcción del Estado nación son reiterativos los casos de divisiones radicales, lo que incluso ha permitido hablar de que las diferencias políticas no obedecen a aspectos ideológicos, sino que básicamente obedecen a "odios heredados" que se retroalimentaban en diferentes coyunturas. Este fue el caso durante los años de la primera independencia, entre 1810 y 1816, más conocido como el periodo de la Patria Boba. Lo mismo se podría decir durante los años de la Gran Colombia y las divergencias entre Simón Bolívar y Francisco de Paula Santander, que llevaron incluso a que este último organizara un atentado en su contra, acontecimiento conocido con el nombre de la conspiración septembrina en 1828 .

Tras la muerte de Bolívar, y la breve etapa de usurpación del poder presidencial por el general Urdaneta, en 1832 se abrió campo a una nueva constitución, en la que, tras la separación de Ecuador y Venezuela, se adoptó el nombre de República de la Nueva Granada. En plena Asamblea Constituyente se eligió al General Santander como presidente provisional, y al año siguiente se ratificaría en el cargo tras las elecciones para el periodo $1833-1837^{2}$. A su llegada al poder, Santander, a pesar de haber dicho que trabajaría porque cesaran los odios del partido, empezó a remover viejas heridas del pasado. Una de sus primeras medidas fue la disminución de los efectivos del ejército, afectando un ala de importantes caudillos militares afectos a la causa bolivariana. Esta confrontación dio lugar a una primera división partidista entre "civilistas" y "militaristas", que seguirían en pugna por

\footnotetext{
${ }^{1}$ Fernán, González, Para leer la política. Ensayos de Historia Política Colombiana, (2 Tomos) (Bogotá: CINEP, 1997), 115.

${ }^{2}$ González, Para leer...,106-107.
} 
muchos años más. Se escenificaron conatos de revueltas armadas lideradas por antiguos militares bolivarianos que fueron duramente reprimidas por Santander con ajusticiamientos, penas de muerte y exilios. Estos hechos motivaron el despertar de un fuerte inconformismo en algunas regiones del país, en donde lo tacharon con el epíteto de tirano.

A su vez, dentro del propio partido del gobierno se empezaron a presentar fuertes divisiones entre un ala moderada y otra radical o exaltada, que reproducía el antagonismo vivido entre girondinos y jacobinos. Asimismo, Santander tuvo que soportar la promulgación de algunos sermones y escritos de religiosos en su contra, lo que demuestra las fuertes desavenencias que su gobierno generaba, desatando una profusa guerra de papeles y libelos.

El gobierno de acentuado corte "liberal" de Santander, continuó suscitando una gran oposición en su intento de socavar poderes ya constituidos, como el que detentaban el ejército y el clero, así como en el delicado tema de la educación. Al ordenar la restitución de las cátedras de autores como Bentham y del Conde De Tracy, Santander "agitaba hondos resentimientos", y de acuerdo con sus opositores, se decía que su gobierno atacaba "la religión de sus padres" y arrancaba "del corazón de los granadinos las puras y antiguas creencias del catolicismo, enseñándoles tan inmorales y perniciosas creencias"3.

Igualmente, cabe decir que desde 1835 se habían agudizado las diferencias ideológicas y personales entre radicales y moderados, con motivo de las elecciones para el cargo de vicepresidente de la república. Al final ganó el candidato de los moderados, José Ignacio de Márquez, sobre los candidatos José María Obando y José María Azuero, presentados por los radicales cercanos al presidente Santander ${ }^{4}$. Pero con motivo de las elecciones presidenciales para el cuatrienio 1837-1841, las dos facciones empezaron a delimitarse más claramente. Santander promovió desde 1836 la candidatura del general José María Obando, de amplia trayectoria en la vida política del país. El ambiente político se caldeó aún más al conocerse que el principal opositor a Obando sería el vicepresidente Márquez, dando lugar a mutuas recriminaciones y señalamientos.

A Obando se le endilgaba haber defendido la causa realista durante las luchas de independencia, así como ser el autor intelectual de la muerte del prócer José Antonio Sucre, en confusos hechos ocurridos en el año 1830. Asimismo, se le recriminaba el hecho de haber sido postulado por el mismo presidente Santander, en un hecho sin precedentes en la corta historia republicana de la nación y que implicaría la continuación de un gobierno que había despertado muchas antipatías. Además, se decía que era un contrasentido que un personaje como Santander que se había caracterizado por su defensa de un orden civilista, estuviera ahora a favor de que el poder lo asumiera un hombre de espada. Por su parte, los opositores a Márquez argüían que este se encontraba "legal y moralmente" impedido para postularse a la presidencia por aspectos de inconstitucionalidad, ya que se consideraba que él no podía aspirar ni ejercer la presidencia mientras estuviera en posesión del cargo ${ }^{5}$.

Al final Márquez ganó las elecciones, pero asumió la primera magistratura en medio de una profunda sectarización política, que afectaba profundamente la legitimidad de su gobierno. Las posiciones antagónicas se seguirían radicalizando hasta las antípodas. En agosto de 1837, Márquez removió de sus cargos a Florentino González y a Lorenzo María

\footnotetext{
3 José Manuel Restrepo, Historia de la Nueva Granada 1832-1845 (Tomo I) (Bogotá: Editorial Cromos, 1952),67.

${ }^{4}$ González, Para leer...,109.

${ }^{5}$ González, Para leer...,112.
} 
Lleras, antiguos coeditares de La Gaceta de la Nueva Granada y quienes fungían hasta entonces como ministros de hacienda y del interior, respectivamente.

A partir de este momento es que se empieza a dar la confrontación entre La Bandera Nacional y El Argos. Y como señala Gustavo Arboleda, "Oposicionistas y ministeriales, todos usaron a la vez armas reprobadas; seducían, halagaban, atraían, intimidaban y ponían en juego cuantos recursos les sugirió su entusiasmo y malignidad"6. Según Alberto Lleras Camargo, este tipo de papeles diminutos y trabajosamente impresos, se caracterizaron por constituir todo un género literario y político sarcástico y socarrón, en ocasiones en tono urticante y en otros adulatorio, que tuvieron una extraordinaria eficacia, si se atiende a la ínfima circulación que podían tener, pero que sirvieron para encender las pasiones políticas del momento a través de un constante duelo verbal ${ }^{7}$. Las hostilidades políticas, de profunda índole personal, dieron lugar al surgimiento de los periódicos de opinión pública, instrumentalmente adaptados a los intereses y requerimientos de cada facción, aunque el lema moral que los justificaba en ambos casos, tanto para quienes atacaban al gobierno como para quienes lo defendían, era la búsqueda del bien común o el interés general, que al parecer los "otros" ponían en riesgo con sus actitudes antipatrióticas, injustas o ilegales.

\section{Las justificaciones morales para desatar la guerra verbal: aparición de La Bandera Nacional y El Argos}

El 22 de octubre de 1838 apareció La Bandera Nacional, en el que bajo el liderazgo del general Santander, se sumaron las plumas de jóvenes abogados, médicos y filósofos, como era el caso de Florentino González, Luis Vargas Tejada, Ezequiel Rojas, Lorenzo María Lleras y José Duque Gómez, egresados en su mayoría del Colegio Mayor de Nuestra Señora del Rosario, impregnados de ideas libertarias y antidespóticas. Desde sus primeras columnas es interesante observar la manera como los escritores de La Bandera se esforzaron por convencer a sus lectores de la legitimidad moral que los asistía para declararse en oposición al gobierno de Márquez. Sin estar constitucionalmente reconocido el derecho a la oposición, pero sí el de la libertad de imprenta, los argumentos se orientaron hacia la defensa de los valores republicanos propios de una ciudadanía atenta a la preservación de una moral pública, así como a la difusión del legado ilustrado que los conminaba a dar luces a una opinión pública que daba sus primeros pasos. Desde el primer número de La Bandera, sus editores hicieron explícito el fin moral de su publicación y los objetivos políticos que perseguían:

Seguros de la justicia que nos asiste, convencidos de la santidad de la causa que ha tiempo defendemos, nos presentamos en la arena armados únicamente de la fuerza del raciocinio, y esperamos con ánimo tranquilo el triunfo de la opinión. [...] Nuestra divisa es la independencia granadina, su constitución, su libertad, el honor nacional, el cumplimiento de las leyes, el orden, la paz y el adelanto de los intereses intelectuales, morales, políticos y materiales del país ${ }^{8}$.

Para personajes afines a la causa del grupo opositor, como en el caso del general Obando, la prensa era valorada como "el único tribunal que quedaba ya para quejarse contra el gobierno", y un periódico de oposición era, a su vez, un medio legítimo de "reprimir" los

\footnotetext{
${ }^{6}$ Gustavo Arboleda. Historia contemporánea de Colombia (Tomo 2) (Bogotá: Banco Central Hipotecario, 1990), 148.

${ }^{7}$ Alberto lleras, Mi gente (Volumen I) (Bogotá: Alberto Lleras@, 1976), 37.

${ }^{8}$ La Bandera Nacional. N. ${ }^{\circ}$ (1838).
} 
abusos del poder, obligándole a mantenerse dentro de los “justos” límites constitucionales, "para no forzar a la nación a recurrir a las armas".

Como se observa, el lenguaje estaba profundamente cargado de elementos retóricos y metafóricos, con variantes románticas y republicanas. La oposición se representaba a sí misma como unos "centinelas vigilantes y leales a la constitución". Por lo tanto, su causa política, concebida como una "lid patriótica", adquirió los rasgos más elevados dentro de la moral republicana que imperaba por entonces. Ellos eran los "defensores valerosos" de la "bella causa" de la libertad. Así iban configurando, con este lenguaje y sus respectivas representaciones, su propia trama heroica, muy cercana a una visión mesiánica.

Un hecho interesante que se puede observar en el rastreo de la prensa de oposición del período, es la cita frecuente de pensadores liberales europeos que inspiraban sus luchas ideológicas. Tal es el caso de La Bandera que recurría a las ideas de Benjamin Constant, quien decía: "los pueblos, que con el objeto de gozar de la libertad que les conviene, recurren al sistema representativo, deben ejercer vigilancia activa y constante sobre sus mandatarios para ver si cumplen exactamente con su encargo o si defraudan sus votos y deseos", a lo que agregaban que "si este texto ha servido para escribir contra la administración del general Santander, es menester que también nos sirva para censurar la administración del señor Márquez" ${ }^{\prime 10}$.

A pesar del tono personalista de los enfrentamientos verbales, es interesante señalar que los editores de La Bandera adujeron que su oposición no era ni ilegal, ni subversiva y que nunca optarían por las vías de hecho para hacer frente al gobierno, ya que ellos confiaban en el poder civilizador de la prensa. En la edición número 13 del 14 de enero de 1838 , los editores de La Bandera hacían gala de un profundo conocimiento de los sistemas políticos, destacando nuevamente su profundo respeto por el sistema republicano:

... nuestra oposición no es ni puede ser al sistema político que rige la república; porque ni somos godos para querer la dependencia de la Nueva Granada de antigua metrópoli, ni monarquistas para hacerle la guerra al sistema republicano, ni absolutistas para odiar las leyes que fijan a la autoridad sus límites, ni fuimos partidarios de la dictadura [en alusión a Bolívar] para procurarle otra al país, ni de la usurpación [en alusión a Urdaneta] para promover una segunda, ni fanáticos, ni supersticiosos para desear el viejo reinado colonial de fanatismo y superstición ${ }^{11}$.

En medio de la aspereza del debate, algunos de los escritores de La Bandera Nacional hicieron graves acusaciones y amenazas que caldeaban aún más los ánimos políticos. Se llegó incluso a decir que no se dudaría en recurrir a las armas para poner sus vidas a salvo, especialmente desde el momento que aparecieron en la escena política la denominada Sociedad Católica, cuyos miembros no menoscababan en términos rebuscados para hacer explícita su defensa de la religión y el gobierno" ${ }^{12}$. En un artículo titulado "Seguridad personal”, firmado por Lorenzo María Lleras, se expresaba lo siguiente:

\footnotetext{
${ }^{9}$ José María Obando, Apuntamientos para la historia (Medellín: Editorial Bedout, 1978), 267.

${ }^{10}$ La Bandera Nacional. N. ${ }^{\circ} 8,2$ (1838).

${ }^{11}$ La Bandera Nacional. N. ${ }^{\circ} 13$ y 14 (1838).

${ }^{12}$ Frank Safford, "Formación de los partidos políticos durante la primera mitad del siglo XIX”, en Aspectos polémicos de la Historia Colombiana del siglo XIX: Memorias de un Seminario (Bogotá: Fondo Cultural Cafetero, 1983), 9-50.

Safford afirma que en el seno del partido "ministerial" - o de los "moderados" como él mismo los denomina hubo una división de fracciones, entre "un ala moderada racional o sofisticada, de vocación cívica” y un ala que
} 
Ya los escritores públicos son amenazados escandalosamente, con desprecio de las leyes y de las autoridades constituidas, de la manera misma que se hiciera en la época aciaga de la dictadura y militar tiranía [...] Todo esto prueba, pues, que se carece de seguridad individual y que los ciudadanos tienen que apelar a su valor personal y al de sus amigos para defenderse de ataques que las leyes y los magistrados no tienen la fuerza bastante para reprimir [...] En tal virtud hago presente a ustedes que, así yo como mis numerosos amigos de la oposición andaremos constantemente armados para repeler la fuerza con la fuerza, y a escarmentar a los que se atreven a atentar contra nuestras vidas. Quedan, pues, nuestros adversarios intimados de nuestra resolución ${ }^{13}$.

De igual manera, la paulatina configuración de un espacio público de deliberación política desde el margen de la oposición tomó forma a partir de la proliferación de una serie de figuras retóricas plenas de metáforas y analogías con las que, a la vez que exaltaban su virtuosismo patriótico, se mofaban abiertamente de sus contrincantes, enraizando los sectarismos en el imaginario político de la época. Uno de los sarcasmos más brillantemente empleados por la oposición y que apuntaló los principales puntos de debate entre La Bandera Nacional y El Argos, quedó consignado en el artículo "Nuevo diccionario para la presente época", mediante el recurso del retruécano, es decir, definiendo una palabra a partir de su antónimo. Me permitiré citar en extenso dicho artículo, ya que ilustra los principales puntos de confrontación ideológica entre los bandos en pugna y a partir de los cuales empezaron a hacer carrera las principales estigmatizaciones de tipo partidista:

Liberal, él que sostiene de palabra o por escrito todas las aberraciones del poder ejecutivo, y ataca los actos de la anterior administración.

Patriota, él que ha sostenido la elección del doctor Márquez, y sostiene hasta sus errores gubernativos, voluntarios e involuntarios.

Gran ciudadano, él que escribe denuestos e injurias contra los patriotas calificados como tales por la opinión pública, que tuvieron la osadía de opinar por Obando o por Azuero.

Faccioso, él que censura los actos ilegales o de abuso de poder del presidente de la república. Perturbador, él que habla o escribe bajo la garantía de la ley de imprenta contra los desaciertos del gobierno, o que le parecen tales.

Escritor Ministerial, él que para merecer un empleo que solicita, o para corresponder el que ha recibido, o para conseguir una moratoria por deuda al tesoro público, redacta un papel de improperios contra los que dicen que el presidente no procede desapasionadamente, y de panegíricos a su excelencia.

Safford denomina como "fanáticos", dando lugar a una diferencia de mentalidad muy interesante dentro de la misma corriente partidista. Para este mismo autor, los "fanáticos" eran los soldados rasos del partido o si se quiere de estirpe más popular: "...fueron ellos los que formaron la Sociedad católica como arma política y agitaron la cuestión religiosa".

${ }^{13}$ La Bandera Nacional, N. ${ }^{\circ} 45$. Bogotá: 19 de agosto de 1838, p. 4. Una característica dentro del período estudiado es la forma como los lenguajes políticos se radicalizan y el animus belli se hace más explícito. Para el caso me permito citar en extenso una "hoja suelta" de autoría de la Sociedad Católica y que los editores de La Bandera Nacional transcribieron en la edición No. 24 del 1 de abril de 1838: “¡Granadinos! ¡Cuántas faltas, cuántas infracciones horrendas no se cometieron en la administración pasada! [la de Santander] [...], más ahora estos nuevos Gracos, con una sed alterada de sangre y de venganza, quieren hundir este pueblo en los horrores de la anarquía y saborearse en banquetes de carne humana. ¿Permitiréis que estos caníbales violasen la santidad del Evangelio? ¡Ministros del Santuario! ¿permitiréis que las orgías jacobinas se enseñoreen este país? Pues temblad si el gobierno es destruido; la Nueva Granada no resistirá más: su sufrimiento se agota y ríos de sangre inundarán esta tierra si sus esperanzas salen burladas. El orden o la muerte, he aquí nuestros últimos votos”. 
Firmeza, decir injurias a roso y velloso a los que no creen que el poder ejecutivo marche por la vía recta y conveniente.

Energía, remover de sus destinos a empleados amigos de las instituciones, que saben respetar el orden público y sacrificarle sus resentimientos.

Imparcialidad, conferir destinos a los que fueron contrarios a la elección del doctor Márquez a razón de cinco por ciento de los de su partido.

Hemos definido estas palabras para que los electores de la Nueva Granada y de fuera de ella, puedan entender todos los impresos que en cada semana salen de imprentas de Bogotá ${ }^{14}$.

Así, ante los ataques aparentemente "injustos" de la oposición, personajes cercanos al gobierno de José Ignacio de Márquez, como Lino de Pombo, Rufino Cuervo, Alejandro Vélez, Juan de Dios Aranzazu, Ignacio Gutiérrez Vergara y Joaquín Acosta, entre otros, y que según La Bandera Nacional fueron en sus días liberales por repugnancia a la dictadura militar de Bolívar, resolvieron asociarse y crear un periódico que respondiera a los comentarios agraviosos de La Bandera Nacional. De esta manera nace El Argos el 26 de noviembre de 1837, para contraargumentar todos los ataques de la oposición. Y en efecto, la lucha comienza a hacerse cruda y personal ${ }^{15}$.

Durante su corta existencia, El Argos se vio obligado a justificar política y moralmente su existencia y su decidida labor de apoyo al gobierno de Márquez. En unos casos apelaban a la defensa del orden y de las instituciones, lo mismo que al respeto por la expresión de la voluntad general de la nación en las urnas, para salvaguardar el sistema político representativo, condenando de paso a quienes obraban de manera contraria. De igual manera, cuando la oposición quería someter al escarnio público al gobierno, El Argos servía de escudo al gobierno para apaciguar el inconformismo político y en su lugar anteponer los criterios de "justicia, legalidad y conveniencia" con los que este actuaba, como por ejemplo frente a las acusaciones de sectarismo por la salida del gabinete ministerial de Lorenzo María Lleras y Florentino González, adeptos al general Santander:

... todo gobierno de la tierra, y mucho más los que son débiles por su estructura, y porque aún no tienen la sanción del tiempo, deben rodearse de agentes de cuya buena voluntad estén seguros, que estén identificados con ellos en principios y en sistema, y que con celo y perseverancia les ayuden a desempeñar su difícil y arduo encargo. Cómodo habría sido para una oposición que nació antes de haber funcionado el presidente de la República, tener partidarios suyos tan cerca de los consejos de gobierno ${ }^{16}$.

De ahí que el debate político cayera muy fácilmente, una y otra vez, en las incriminaciones personales. Ante la aspereza de un buen número de artículos que publicaba la oposición para demeritar las actuaciones del gobierno, El Argos exigía que el debate se diera en términos más cultos:

... hable usted con más decencia de los altos funcionarios públicos, si quiere que su antipática oposición parezca noble y racional; use usted el lenguaje admitido entre la gente culta, presente

\footnotetext{
${ }^{14}$ La Bandera Nacional N. ${ }^{\circ}$ 12, Bogotá: 7 de enero de 1838, p. 3.

${ }^{15}$ Es preciso señalar que además de El Argos, existieron otros periódicos ministeriales como El Baluarte de Bogotá y El Patriota de Popayán, que se iban lanza en ristre contra los redactores de La Bandera Nacional.

${ }^{16}$ El Argos N. ${ }^{\circ}$ 2, Bogotá: 3 de diciembre de 1837, p. 4.
} 
ideas de un alma elevada, ya que constantemente trata usted de inmundos a los periódicos que revelan y combaten sus planes, y que demuestran sus errores y sus contradicciones ${ }^{17}$.

En muchas otras ocasiones, los redactores de El Argos repelían las críticas de la oposición tomando como pretexto los supuestos excesos en los que había incurrido la administración de Santander en el cuatrienio anterior, período durante el cual "la patria lloró y se vistió de luto" $"$.

Un detalle por resaltar en el debate que El Argos le planteó a los editores de La Bandera Nacional fue el carácter moderado que debería tener una verdadera oposición. Se decía por parte de los ministeriales que la administración de Márquez no temía, ni despreciaba a una oposición "racional y moderada": "Una oposición de esta naturaleza si llegara a existir, sería de un gran bien y sus esfuerzos merecerían gratitud y aplauso. Ella vendría a constituir un nuevo elemento de progreso, de orden y de verdadera libertad". Pero a renglón seguido cuestionaba el beneficio político que la existencia de un grupo de oposición le podría aportar a la consolidación de la república, sobre todo, aludiendo al hecho de su precaria estabilidad institucional: "Que se haya levantado contra su administración una injusta y apasionada oposición, malo, y muy malo es, en un pueblo nuevo, en donde los hombres todavía están formando las instituciones"19.

Fácilmente se puede empezar a advertir cómo en cada uno de los bandos en disputa empezaban a hacerse más explícitos ciertos rasgos ideológicos. Si bien se podría afirmar que en esencia ambas facciones se adherían a cierto legalismo liberal, al igual que a ciertos valores republicanos, desde la tribuna de La Bandera Nacional se promovía la idea de una ciudadanía emancipada y si se quiere, radicalmente liberal, mientras que desde El Argos se defendía la idea de una mayor estabilidad institucional, en procura del orden que tanto requería la naciente República neogranadina.

Sin embargo, era evidente que primaban las acusaciones personales como una estrategia para desacreditar al contendor político. En muchas ocasiones, El Argos señalaba que "la guerra" que se había emprendido contra el gobierno de Márquez no era una "guerra de principios, si no de personas". Y finalizaba diciendo:

...que el periódico que sostiene esta campaña rebusca cargos, los abulta y los desfigura, para acriminarlo y desconceptuarlo: que a falta de hechos, acusa las intenciones y presenta, en cláusulas pomposas, planes y miras que no pueden existir, de persecución, de retrogradación, de innobles venganzas: y estas producciones se distribuyen con profusión en todas las provincias, después de haberse trabajado en organizar además en ellas, juntas o sociedades auxiliares para la empresa de despopularizar a los altos funcionarios ${ }^{20}$.

Por lo tanto, a los ojos de El Argos, no se desarrollaba en realidad una oposición racional y patriótica. Lo que había, desde su sesgo particular de valorar las cosas, era más bien toda una campaña de calumnias y difamaciones que recaía especialmente sobre las personas al frente de la administración pública. En consecuencia, la deslegitimación moral y política de la oposición se dirimía en últimas en torno a un problema de alteridad y exclusión. Partiendo del hecho de que el gobierno de Márquez representaba la voluntad general del

${ }^{17}$ El Argos N. ${ }^{\circ}$ 2, Bogotá: 3 de diciembre de 1837, p. 4.

${ }^{18}$ El Argos N. ${ }^{\circ}$ 4, Bogotá: 17 de diciembre de 1837, p. 1.

${ }^{19}$ El Argos N. ${ }^{\circ}$ 4, Bogotá: 17 de diciembre de 1837, p. 1.

${ }^{20}$ El Argos N. ${ }^{\circ}$ 4, Bogotá: 17 de diciembre de 1837, p. 3. 
electorado, se asumía que quien postulara su descontento por fuera de dicha voluntad, es decir, por fuera del soberano, era un enemigo público, sobre el que además recaía todo el descrédito político por situarse por fuera de la moral patriótica que se hallaba representada en el gobierno. Lo que verdaderamente indignaba era la animadversión personal a ultranza que reflejaba una actitud "pueril" de aquellos que pretendían que la administración pública se orientara en función del "gusto de ciertos individuos". Para ellos, el verdadero patriotismo no tenía otro "resorte" que el bien "procomunal", y por la misma razón "no es patriota el que no sabe sacrificar a él sus propias pasiones" 21 .

Como vimos anteriormente, las discordias también se centraban en la disputa por cuestiones terminológicas, en particular en temas como la diferencia entre gobiernos militaristas y civilistas, entre retrógrados y progresistas o entre serviles y liberales. Los editores de El Argos les criticaban abiertamente a los editores de La Bandera su tono extremadamente ilustrado, abstracto y demagógico para referirse a la discusión sobre los grandes problemas nacionales o sobre diversas actuaciones del administrativo, todo esto con el ánimo de descalificarlos ante la opinión pública a la cual se intentaban dirigir. La desconfianza hacia los lenguajes más elaborados de la oposición, que los partidarios del gobierno asumían como efectistas y artificiosos, les servía de excusa perfecta para promover un debate en un lenguaje más llano, lo que sin duda constituía toda una disputa por la verdadera representación política del pueblo y sobre la forma como se deberían dirigir los "publicistas" ante la opinión pública en formación:

... en verdad nuestra intención no ha sido hacer a dichos editores [los de La Bandera Nacional] inculpaciones sobre los principios abstractos que profesen en ciencias políticas [...]; nosotros no hemos intentado ni intentamos entrar en exámenes sobre el particular. Nuestra cuestión no es sobre teorías gubernativas; ella versa sobre la profesión de las personas que han de gobernar la República [en alusión a la disputa sobre si el presidente debía ser un civil o un militar] ${ }^{22}$.

\section{Las dicotomías insalvables: la estigmatización del opositor político}

Uno de los aspectos que más llama la atención de la disputa entre la oposición santanderista y el gobierno de Márquez es la manera como se forjaron unas primeras formas de identidad partidista a partir de la descalificación del opositor político. Más que la identificación con un determinado ideario político, imperaban, como se ha dicho anteriormente, las filiaciones personalistas o las adscripciones grupales en torno a un determinado líder. En este sentido son muy importantes las denominaciones con las que los miembros de uno y otro bando se interpelaban, y que les servían tanto para identificarse como para diferenciarse.

Tanto en el caso de La Bandera Nacional como de El Argos se recalcaban constantemente esta suerte de vicio político. Para el caso se puede citar la queja reiterada del grupo adepto a Santander, quiénes reclamaban para sí el derecho constitucional de vigilar las actuaciones del gobierno, pero que eran objeto de toda clase de improperios por parte del "partido" ministerial:

...a esta oposición sea que use la imprenta, o que levante su voz en el Congreso, se le llama facciosa, perturbadora, sediciosa, enemiga de la patria y del gobierno; y a los hombres que la hacen, se les llena de improperios y de calumnias, se les denomina ambiciosos banderizos,

${ }^{21}$ El Argos N. ${ }^{\circ}$ 5, Bogotá: 24 de diciembre de 1837, p. 4.

${ }^{22}$ El Argos N. ${ }^{\circ}$ 6, Bogotá: 31 de diciembre de 1837, p. 1. 
facciosos, ingratos, y se agota el diccionario de las injurias para desacreditarlos, perseguirlos y hasta hacerlos odiosos. Con semejantes recompensas, ¿puede esperarse que la doctrina enseñada en la clase de derecho constitucional haga progreso en la Nueva Granada por medio de una práctica saludable, moderada y oportuna? Temeridad sería esperarlo... ${ }^{23}$.

No bastaba solo con debatir quién podía ejercer legal o moralmente la función de oposición, sino que también era fundamental establecer quiénes eran patriotas y quiénes antipatriotas, lo mismo que quiénes se hacían del lado del progreso y quiénes eran retrógrados, y en últimas, quiénes eran los adalides de la libertad y quiénes pretendían forjar nuevas formas de despotismo o servilismos.

En consecuencia, es factible afirmar que a partir de estas categorías dicotómicas se establecieron antagonismos insalvables sobre los cuales se forjaron los cimientos de los agrupamientos e idearios políticos que una década más tarde ya podemos distinguir con nombres propios: liberales y conservadores.

Lo interesante en toda esta disputa es mostrar la manera como rechazan las imputaciones entre sí los que sumían la defensa del gobierno y sus opositores. Se podría decir que, en esencia, ambos bandos defendían un ideario liberal, e igualmente se consideraban progresistas y patriotas. Los denuestos y anatemas van y vienen, y en esta medida el opositor o contendor político encarnaba el germen de la mala política. En definitiva, el problema era un asunto de alteridad, de quién era el otro, quién era el opositor, quién era el disidente, ya que ambos grupos promovían el mismo lenguaje político desde sus respectivos periódicos. Esto se puede ilustrar tratando de seguirle el rastro a cada una de las disputas dicotómicas que a continuación se detallan.

\subsection{De patriotas $y$ antipatriotas}

Hemos visto cómo desde las tempranas sociabilidades que se forjaron durante la época de la Gran Colombia se fueron perfilando identidades antagónicas que con el pasar de los años se fueron bifurcando por sendas irreconciliables. Interesa preguntarnos en este ejercicio de indagación sobre la cultura política del período estudiado, qué tan unívocas eran algunas denominaciones como la de patriotas o la de progresistas, a las cuales dedicaron extensas columnas en ambos periódicos. ¿Se podría vincular a alguno de los bandos en pugna por su adscripción a determinado ideario político, que permitiera identificar con facilidad quiénes eran los verdaderos patriotas o quiénes los verdaderos hombres de espíritu progresista? La respuesta a este interrogante se torna compleja cuando se aborda el estudio de ambos periódicos y encontramos que cada uno quiere abrocharse para sí mismo el rótulo de patriota y de progresista, y de paso, descalificar a su antagonista político.

\section{El patriotismo de La Bandera Nacional}

Decir patriotismo para los editores de La Bandera Nacional era dejar constancia de su historial de luchas en pro de la defensa de la constitución y contra cualquier atisbo de despotismo renovado:

Esta facción santanderiana o santanderista, es ya un poco vieja. Nació cuando Bolívar nos quiso dar boliviana dictadura: entonces sus escritores y no escritores llamaron al partido que resistió a Bolívar y defendía la constitución, facción de Santander, facción ilustre y patriótica por el objeto que se propuso y por sus gloriosos resultados. Facción llamaban los ingleses a los que

${ }^{23}$ La Bandera Nacional N. o 46, Bogotá: 19 de agosto de 1838, p. 2. 
con Washington defendían la independencia americana. Facción bolivarista llamaron los españoles a los patriotas que guiados por Bolívar sostenían la independencia. Facción santanderista llamaron los dictatoriales a los amigos de las leyes que defendíamos la constitución de Cúcuta; hoy en 1838 tenemos únicamente en la pluma del Argos, y de otros señores ministeriales, la facción santanderista, para deprimir a los patriotas progresistas, que, unidos al gobierno por el amor al orden y a las instituciones, no difieren de los ministeriales, pero que por no aplaudir la política y conducta gubernativa del presidente Márquez, los censuran y vituperan. Pero llámenos facción, partido, bando, o como quieran, nuestra conducta será siempre la misma, e iguales serán nuestros principios políticos, las injurias ni nos arredran ni nos precipitan. Nuestro patriotismo tiene fundamentos sólidos, miras desinteresadas, objetos santos y fines laudables ${ }^{24}$.

El temor ante cualquier nuevo intento militar para usurpar el poder gubernamental obligaba a los opositores a elevar una nueva moral en torno al significado de la palabra patriota. Para ellos el patriota no era el soldado, sino el ciudadano de comprobadas virtudes republicanas. Quizás por eso se mofaban de las distinciones que en algunos países vecinos de la Nueva Granada le continuaban haciendo a los bustos de los próceres de la independencia. Las medallas y condecoraciones las asimilaban con una especie de fetiches, actitud que era muy propia de los militares que con tanto celo exhibían públicamente sus títulos y charreteras. La siguiente cita, publicada en La Bandera Nacional el 11 de febrero de 1838, permite ilustrar mejor la anterior aseveración:

Felizmente en los estados a que dio nacimiento la disolución de la República de Colombia, ya se ha olvidado la moda de cargar el busto [...] Pero allá en el Perú y Bolivia todavía continua el uso de llamarse "condecorados con el busto del libertador Bolívar", y seguramente el de cargarlo al cuello pendiente de la cinta tricolor. Tan ridículo nos parece todo esto, como sería el cargar las medallas que de orden de nuestros cabildos se acuñaron con la augusta proclamación de los reyes católicos ${ }^{25}$.

Pero uno de los aspectos que más le reclamaban los editores de La Bandera Nacional a sus colegas de El Argos, era el obrar movilizados por pasiones personales, a la manera de gregarios, lo cual no solo los impedía para formarse juicios acertados sobre la marcha de los diferentes negocios públicos que ejecutaba el gobierno, sino que además también les impedía poseer algo más sustancial, de acuerdo con el espíritu de la época: los publicistas ministeriales carecían de libre albedrío y voluntad propia.

\section{Las réplicas de $\boldsymbol{E l}$ Argos}

Por su parte, los editores del periódico El Argos entraban en liza pública ironizando el argumento que había hecho carrera desde los inicios de la administración de Santander, según el cual

sólo han sido patriotas los que escribieron contra el general Bolívar desde países extranjeros, y los que redactaron aquel periódico de triste recordación [El Cachaco], despedazando todas las reputaciones y poniendo en combustión los partidos políticos [...] Los que pensaban de una

\footnotetext{
${ }^{24}$ La Bandera Nacional N. ${ }^{\circ} 43$, Bogotá: 5 de agosto de 1838, p. 1.

${ }^{25}$ La Bandera Nacional N. ${ }^{\circ} 17,4$ (1838).
} 
manera diferente a la de aquel pequeño círculo, fueran cuales fuesen sus servicios a la patria, no eran patriotas ${ }^{26}$.

Los editores de El Argos definieron lo que en su concepto era la verdadera acepción de esta palabra:

En la Nueva Granada siempre se había llamado patriotas, con la verdadera acepción de esta palabra, $1^{\circ}$. A los hombres denodados que en 1810 alzaron el grito de independencia para derribar el poder español; $2^{\circ}$. A los que sostuvieron la lucha sangrienta de la revolución, derramando su sangre y sacrificando sus propiedades en las aras de la patria; $3^{\circ}$. En fin, a los que tuvieron la gloria de dirigir a los pueblos, ya en la campaña, ya en el gabinete, sin plegarse jamás, ni a las amenazas de los enemigos, ni a los caprichos de los revoltosos, hasta fundar un gobierno republicano, propio para hacer libres y felices a los granadinos. Todos estos hombres, que han trabajado tanto por la independencia y la libertad de su patria, se han denominado patriotas justamente, y patriotismo, el sentimiento vigoroso que los animaba por el bien y felicidad de su país ${ }^{27}$.

No obstante, los redactores de El Argos adicionaban otras características que permitían establecer de manera más nítida el perfil del verdadero ciudadano patriota, características que por supuesto no eran reconocidas en sus opositores. Uno de estos aspectos era la crítica de los redactores de El Argos al apoyo que le brindaron los adeptos al expresidente Santander a la candidatura del general Obando durante las elecciones de 1837, avivando el muy conocido debate entre militares y civilistas.

Decidan los hombres imparciales quiénes han sido los verdaderos patriotas. ¿Lo serían los que pretendieron darnos un presidente militar? No: es claro que más bien lo fueron los que apeteciendo garantías, y una verdadera libertad, bajo el mando de un magistrado civil, se decidieron por la elección del señor Márquez: y ellos lo han sostenido y sostienen, apoyados en una gran mayoría de granadinos que piensan del mismo modo ${ }^{28}$.

Pero la defensa del gobierno era, en último término, el punto clave. Sí como se ve, las posiciones del gobierno y de la oposición eran bastante cercanas en su renuencia a las simpatías por los militares, tema al que ambos bandos a su vez le hacían el quite en sus mutuas acusaciones, quedaba por dirimir una cuestión más fundamental: ¿Quiénes estaban del lado del gobierno y quiénes no? El valor supremo al que apelaba La Bandera era el patriotismo constitucional, mientras que para la gente de El Argos este residía en la defensa del gobierno.

Para los defensores del gobierno, la voluntad general de la nación se había expresado en las elecciones, permitiéndole llegar a Márquez hasta la primera magistratura. Y por eso, hacían un mayor énfasis en este punto, trayendo a colación la situación en otros países del mundo, con un afán explícito de incorporarse a una civilidad política universal, en la que eran fundamentales el orden y el respeto por la institucionalidad democrática:

En todos los países en donde se conocen bien los elementos del gobierno representativo, y se practican con franqueza y lealtad, el calor eleccionario se calma desde que la nación pronuncia

\footnotetext{
${ }^{26}$ El Argos N. ${ }^{\circ}$ 2, Bogotá: 3 de diciembre de 1837, p. 3.

${ }^{27}$ El Argos N. ${ }^{\circ}$ 2, Bogotá: 3 de diciembre de 1837, p. 3.

${ }^{28}$ El Argos N. ${ }^{\circ}$ 2, Bogotá: 3 de diciembre de 1837, p. 3.
} 
su voluntad soberana: los ciudadanos que, movidos por interés a su patria, se agitan por elevar al poder supremo al que más digno juzgan de este honor, no tienen candidato desde que la mayoría les dio un magistrado; y sostenerlo entonces, ayudarlo y respetarlo, es una misión que desempeñan por honor y patriotismo. Si de otro modo se obra, se da un claro testimonio de intolerancia política, de insensato orgullo, y de una ridícula y arrogante presunción, cuando $\operatorname{menos}^{29}$.

Estar o no estar del lado del gobierno, he ahí el aspecto decisivo: “... el que, en la Nueva Granada, sostenga la actual administración en tanto que ella marche por la vía legal, es un patriota progresista; el que trate de despopularizarla con censuras apasionadas y atrevidas debe calificarse de retrógrado"30; ese era el lenguaje de las pasiones y de las causas justas que utilizaba El Argos.

En última instancia y ante la polarización irreconciliable de ambas facciones, se recurría al argumento de que el tribunal imparcial de la opinión pública sería quien emitiría su juicio para desenmascarar a aquellos que en realidad atentaban contra el espíritu patriótico y ponían en riesgo la unidad nacional y el bienestar común; y así mismo, quiénes ejercían una recta política y quiénes hundían al país en las pasiones propias de la mala política.

Pero quizás esta era la ficción mayor a la que apelaban ambos bandos en sus inagotables disputas políticas y morales: la de convocar a una opinión pública nacional, racional e imparcial, que terminaría por darles la razón. En definitiva, la ecuación "patriotismo y moralidad" ha sido una bella fórmula política para movilizar todo tipo de pasiones, tanto las de los más aguerridos, como las de los más incautos.

\subsection{De progresistas y retrógrados}

Otra discusión de este tipo en la que se trenzaron activamente El Argos y La Bandera Nacional, fue la relacionada con la diferencia entre progresistas y retrógrados. Como señala F.X. Guerra, este ha sido un debate típico de la modernidad occidental, y que fue objeto de referencia permanente en Hispanoamérica para tratar de legitimar no solo la consolidación de los Estados nación, sino que también permitió germinar las primeras formaciones partidistas en el continente ${ }^{31}$.

Sin embargo, el caso de la confrontación política aquí estudiado presenta sus rasgos particulares. Mucha tinta corrió de parte y parte para tratar de demostrar cuál bando era realmente progresista y cuál era el partido retrógrado. De nuevo, los grupos en pugna hacían referencia a unos mismos códigos políticos para presentar ante la opinión pública sus argumentos. La línea que dividía a progresistas y retrógrados aparecía a sus ojos de manera nítida, de nuevo, como una división natural, donde ninguno aceptaba ser acusado ante la opinión pública con el denuesto de retrógrado. Retrógrado era el otro.

\section{Los argumentos de La Bandera Nacional}

Política retrógrada: tal es la que se emplea en detrimento de los principios liberales, que tantos sacrificios ha costado establecer. Desde el momento en que el gobierno observa una conducta

\footnotetext{
${ }^{29}$ El Argos N. ${ }^{\circ}$ 2, Bogotá: 3 de diciembre de 1837, p. 3.

${ }^{30}$ El Argos N. ${ }^{\circ}$ 5, Bogotá: 24 de diciembre de 1837, p. 2.

${ }^{31}$ François-Xavier Guerra, "El soberano y su reino. Reflexiones sobre la génesis del ciudadano en América Latina”, en Ciudadanía política y formación de las naciones. Perspectivas históricas de América Latina, coord. por Hilda Sabato (México: Fondo de Cultura Económica, 1997), 37.
} 
hostil con los que no están plegados a su modo de pensar, o no consagran con él en lo que le place, ataca la libertad de pensamiento, viola la independencia de las opiniones, destruye las bases esenciales en que deben estribar los gobiernos libres, con especialidad, los populares representativos $^{32}$.

Para los editores de La Bandera Nacional el progreso se establecía en razón de la libertad racional consagrada en las leyes y el atraso en razón de las prohibiciones de corte personalista. Con base en lo anterior, arremetían contra cualquier actuación del gobierno que ellos consideraran que podía afectar el interés nacional en su marcha hacia el progreso, al lado de las grandes naciones civilizadas que habían dejado atrás cualquier rezago de fanatismo o resistencia.

En muchas ocasiones, mediante la referencia a situaciones políticas en el extranjero, se constituían en el mejor medio de alimentar la hoguera de mutuas recriminaciones. En efecto, en la cita que a continuación se expone, en la que los editores de La Bandera no consideraban apropiado comparar el enfrentamiento partidista civilizado que se vivía durante esta época en los Estados Unidos con lo que sucedía en la Nueva Granada, se involucra por primera vez en los debates a ciertos sectores del clero colombiano, que a través de las sociedades católicas también defendían la causa ministerialista, acusando a la oposición de atea y masónica.

Aquí [en la Nueva Granada] no hay los partidos que allá [se refieren a los federalistas y demócratas de los Estados Unidos]; aquí no hay sino dos pretensiones, la una de hacer retrogradar al país y la otra de hacerlo progresar [...] La primera la favorecen ciertos hombres que, por su timidez, y tal vez por su hipocresía, pasan por buenos y sensatos; los frailes y tal cual(sic) clérigo fanático; la otra es sostenida por la más brillante de las notabilidades de la revolución. Estas pretensiones dividen irreconciliablemente a los granadinos en Progresistas y Retrógrados. Él que diga que aquí hay otra cosa está equivocado, y perjudicialmente equivocado $^{33}$.

Asimismo, en la defensa de su causa progresista, era muy importante dejar en claro su opinión respecto a temas cruciales en el proceso de construcción de la nación, como era el caso de la educación, del ejército y del clero, frente a los cuales enfatizaba con mayor ahínco sus principios de corte laico, liberal y civilista, anticipando desde entonces los ejes cruciales de las reformas que se introducirían en el país una década más tarde, con las reformas radicales liberales de mediados de siglo. En el caso del ejército, abogaban por una administración civil, conforme a las leyes políticas ${ }^{34}$; en el caso del clero se mostraron partidarios de la libertad de culto e incluso llegaron a mostrarse partidarios del matrimonio y del bautismo civiles ${ }^{35}$, lo que a los ojos de otros sectores políticos y sociales era un absoluto adefesio y sin duda, les empezó a granjear hondas animadversiones ${ }^{36}$.

${ }^{32}$ La Bandera Nacional N. ${ }^{\circ}$ 17, Bogotá: 11 de febrero de 1838, p. 1.

${ }^{33}$ La Bandera Nacional N. ${ }^{\circ}$ 6, Bogotá: 26 de noviembre de 1837, p. 2.

${ }^{34}$ La Bandera Nacional N. ${ }^{\circ}$ 10, Bogotá: 24 de diciembre de 1837, p. 2.

${ }^{35}$ En La Bandera Nacional. No. 70 del 10 de febrero de 1839, se publicó una carta dirigida por varios habitantes del Casanare al Congreso, en la que se solicitaban "tolerancia absoluta de cultos para Casanare. Que el matrimonio se solemnice por un alcalde o juez parroquial, en vez de párroco, dándose por aquel las proclamas competentes. Que los libros de partidas de bautismo, casamientos y entierros se lleven por alcaldes parroquiales sin perjuicio si se quiere de que los párrocos lleven también los suyos, pero los que se tengan por auténticos sean los que lleve la autoridad civil".

${ }^{36}$ La Bandera Nacional, No. 45, Bogotá: 19 de agosto de 1838, p. 4. 
También se mostraron favorables a que se introdujera el sistema federal en nuestro país, de modo que se lograra satisfacer el interés general, el cual dudaban ellos que se pudiera producir exclusivamente desde la administración central ${ }^{37}$.

Como era de esperarse, las publicaciones de la oposición fueron recibidas con indignación por parte de El Argos, al señalar que lo único que pretendía La Bandera Nacional era satisfacer caprichos personales de algunos caudillos provinciales, pero, sobre todo, para debilitar el gobierno central que propugnaba por la unidad territorial de la nación.

El ambiente hostil que se generó en torno de las propuestas sugeridas por la oposición, les permitió enarbolar a estos la bandera de la tolerancia política. En un artículo titulado "La intolerancia política es enemiga del progreso", publicado el 8 de julio de 1838, los redactores de La Bandera proponían apaciguar los ánimos exaltados con que los redactores de El Argos contestaban sus cuestionamientos: "No seamos descorteces e inciviles, tolerémonos recíprocamente la diferencia de nuestras opiniones, discutámoslas con calma y sin personalidades, honremos la libertad de imprenta y a nuestra patria común [...] El progreso es hijo de la libertad del pensamiento auxiliado por la imprenta" ${ }^{38}$.

Sin embargo, la brecha entre ambos bandos ya se había profundizado insalvablemente, como lo reconocían los mismos redactores de La Bandera, anunciando los senderos tan disímiles por los que se habían bifurcado las facciones partidistas, un par de meses después de haber querido promover una mutua tolerancia: "Es tan imposible destruir en nuestro país la denominación de los partidos en progresistas y retrógrados, en amigos de las instituciones republicanas y en enemigos de ellas, como es destruir en Inglaterra a Tories(sic) y Whigs" "39.

\section{Los descargos morales de $\mathrm{El}$ Argos}

El debate entre progresistas y retrógrados fue el que más despertó apasionamientos entre los redactores de El Argos. Desde la edición número 2, los adeptos al gobierno de Márquez se propusieron por todos los medios aclarar ante la opinión pública quiénes eran los verdaderos adalides del progreso en la nación. Y de nuevo, sus argumentaciones se encauzaron no tanto por la discusión de determinadas teorías políticas, sino en función de sus actos y de su apoyo irrestricto al gobierno. En un artículo titulado "Progresistas y Retrógrados", planteaban lo siguiente:

La actual oposición, o los editores de La Bandera Nacional, han inventado estas dos voces para calificar a sus devotos y contrarios. Progresistas apellidan a los que, como ellos, no omiten medio de censurar los actos, aun los más indiferentes de la administración, bajo el pretexto de hacerla marchar por el camino de los progresos, es decir de la impopularidad que desean promoverla. Retrógrado es, a su juicio, todo aquel que sostiene al gobierno que no fue elegido por los partidarios de la oposición, aunque lo haya sido por la mayoría de los votos de los pueblos: todo aquel que a fuer(sic) de patriota o sea de egoísta, quiere que haya orden y

\footnotetext{
Para los escritores de La Bandera, la libertad de cultos, el matrimonio civil e incluso, la libertad de enseñanza eran temas esenciales para adelantar al país en la senda del progreso, que además podrían contribuir a atraer la migración extranjera y con ella, el progreso industrial que ya se vivía para entonces en muchas regiones de Europa. Por eso decían, en un tono bastante provocador, que "cuando la constitución impone al gobierno la obligación de proteger una religión, no le concede por esto la facultad de prohibir el ejercicio de cualquiera otra religión, que los naturales del país o los extranjeros naturalizados quieren establecer. [...], más que la sociedad católica bogotana bufe de rabia".

${ }^{37}$ La Bandera Nacional, No. 56, Bogotá: 4 de noviembre de 1838, p. 1.

${ }^{38}$ La Bandera Nacional, No. 38, Bogotá: 8 de julio de 1838, p. 2.

${ }^{39}$ La Bandera Nacional, No. 48, Bogotá: 18 de noviembre de 1838, p. 1.
} 
estabilidad en el ejercicio del poder público, sea quien fuere la persona del que manda. Juzgue ahora el pueblo sensato de la Nueva Granada quien conviene mejor la calificación: si es progresista el que intenta extraviar la opinión, y quizá turbar la tranquilidad pública, haciendo odiosa la administración presente con cargos fútiles que se presentan con el nombre de graves, apelando a veces a personalidades, a veces a amenazas. Y si es retrógrado él que no trata de poner trabas, sino por el contrario, de facilitar la acción administrativa por el bien de la paz y del reposo, del orden y prosperidad de la Nación ${ }^{40}$.

A través de diferentes columnas, los redactores de El Argos le hicieron el quite a los epítetos injuriosos de retrógrados que la oposición les hacía a ellos y al gabinete ministerial de Márquez. Uno de los argumentos de que se valió el periódico ministerial para recusar los dicterios lanzados por La Bandera Nacional, y no quedarse debatiendo exclusivamente las actuaciones del gobierno, fue el recordarles a los adeptos al general Santander su adhesión a la candidatura del general Obando en las elecciones del año 1837. Por lo tanto, los verdaderos progresistas serían quienes habían acometido, incansablemente, la empresa de "emancipar del dominio militar las altas magistraturas de la República”, mientras que los que deberían apellidarse retrógrados o "estacionarios", eran "los que, después del espléndido triunfo de los pueblos y del perfecto sistema democrático, despechados por el desaire que sufrieron, perseveran en su oposición sistemática y en su tenaz resistencia"41.

Nadie, pues, quería aceptar el deshonroso título de retrógrado, y, por el contrario, cada una de las facciones en disputa procuraba demostrar que los retrógrados eran los otros.

Esta misma crítica al lenguaje demagógico que empleaba la oposición para desacreditar al gobierno de Márquez, se reavivó con motivo de las elecciones de cuerpos colegiados de las Cámaras provinciales y de Senado, así como en las elecciones de vicepresidente de la república, en las que salieron derrotados un buen número de candidatos de la oposición. El Argos desdeñaba las acusaciones de La Bandera Nacional sobre un supuesto triunfo de la aristocracia que hacía retrogradar a la nación en su camino hacia el progreso: “...resucitando odiosas y olvidadas clasificaciones de plebe y nobleza para hacer creer que existe entre nosotros una aristocracia" 42 . Para los editores de El Argos esta era una forma vil y repugnante de ganar adeptos entre el artesanado que ya había empezado a perfilarse como un nuevo actor de la escena política a partir de las "sociedades democráticas" que fundó Lorenzo María Lleras en respuesta a la formación de las "sociedades católicas". Por eso, ellos se mofaban de La Bandera diciendo que "la mayoría de los electores han resultado, por desgracia, retrógrados"43.

\section{Los epílogos de la oposición santanderista}

En mayo del año 1838 el Congreso clausuró sus sesiones concediendo un indulto, por una gran mayoría, a reos condenados por conspiración, traición, sedición y deserción. Para la oposición, este indulto era una clara provocación, ya que se liberaron personas que años atrás se habían insubordinado contra el gobierno de Santander. Al anterior revés político, se sumarían sendas derrotas para la oposición en las elecciones para cuerpos colegiados de las Cámaras provinciales y de Senado, así como en las elecciones de vicepresidente de la república, en la que salió electo el candidato del gobierno, el señor Domingo Caicedo, con

${ }^{40}$ El Argos, No. 2, Bogotá: 3 de diciembre de 1837, p. 2.

${ }^{41}$ El Argos, No. 6, Bogotá: 31 de diciembre de 1837, p. 2.

${ }^{42}$ El Argos, No. 32, Bogotá: 01 de julio de 1838, p.1.

${ }^{43}$ El Argos, No. 33, Bogotá: 08 de julio de 1838, p. 2. 
680 votos, por encima del candidato de la oposición, el doctor Vicente Azuero, quien apenas obtuvo 290 votos. Incluso, en una moción de censura que promovió la oposición contra Márquez por la cesión a particulares de la Salina de Muneque, fue negada tajantemente en la Cámara, demostrándose así la minoría que representaba la oposición en dicho cuerpo legislativo: 44 votos negaron la censura a Márquez, contra 8 a favor de adelantarle el proceso. Pero quizás uno de los hechos más decisivos en el decaimiento de los ímpetus de la oposición tuvo que ver con la decisión del general Santander de no seguir colaborando con la redacción del periódico, como consta en la carta que dirigiera a su editor, Lorenzo María Lleras:

He contribuido con mis artículos y en ellos me propuse sostener los sanos principios del gobierno representativo, advertir al poder ejecutivo de lo que me parecía una aberración suya, defender las garantías de mis conciudadanos, impedir el retroceso del país en el sistema político, y ayudar con observaciones que he creído útiles al progreso de varios ramos de la administración. Ni me arrepiento de lo que he escrito, ni me han sorprendido las injurias que me han prodigado. A ellas juzgué que debía exponerme desde que en vez de convertirme en egoísta o en hipócrita para con la administración actual, tomé la pluma para censurarla, aplaudiendo por otra parte, los actos que me parecían legales o útiles. Yo jamás he rehusado llenar mis deberes por miedo a las diatribas y calumnias. Ahora ya no puedo continuar: primero, porque mi salud está muy deteriorada y tengo que ausentarme frecuentemente de la capital; segundo, porque está a mi cargo una obra larga, complicada y difícil como el proyecto del código militar; tercero, porque ya probé que aquí en la Nueva Granada no se puede hacer oposición al gobierno constitucional sin granjearse ojerizas, enemistades y aún persecuciones; cuarto, en fin, porque me tenía disgustado la idea de que se estuviera creyendo fuera de la Nueva Granada que en esta tierra no podía existir un gobierno si hombres de alguna influencia por sus precedentes le hacía oposición. Esta era una imputación a mi país de que tenía necesidad de libertarlo para su honor y dicha futura. Ya está libre de ella. En la Nueva Granada es ya posible un gobierno legal, aunque se extravíe y gobierne mal aunque tenga una oposición compuesta de hombres de alguna notabilidad y de fuerza moral ${ }^{44}$.

Al parecer esta situación influyó determinantemente para que los editores de La Bandera Nacional se despidieran de sus lectores en marzo de 1839, cuando ya avanzaban en la edición No. 75. Sin hacer mayor mención de las causas que motivaron su decisión, los redactores de La Bandera presentaron de manera lacónica su despedida:

Aviso Editorial. Con este número concluye el tercer semestre de este periódico. Suplicamos a nuestros suscriptores de fuera que aún no han satisfecho su cuota, que lo verifiquen cuanto antes para acabar de cubrir los gastos de la impresión. Nuestras circunstancias peculiares nos fuerzan a suspender por ahora la publicación de La Bandera. Si conseguimos arreglar nuestros negocios de la manera conveniente, volverá a publicarse, y daremos de ello oportuno aviso, a fin de que nuestros antiguos abonados puedan suscribirse de nuevo. Nosotros les damos las gracias más expresivas por la protección que nos han dispensado hasta ahora. También las damos a cuantos ocasionalmente se han dignado favorecernos con sus producciones ${ }^{45}$.

\footnotetext{
${ }^{44}$ Francisco de Paula Santander, Administraciones de Santander, 1834-1835 (Tomo IV). Bogotá: Fundación Francisco de Paula Santander, 1990, 122.

${ }^{45}$ La Bandera Nacional, No. 75, 1 (1839).
} 
José Manuel Restrepo, en su Historia de la Nueva Granada, cuenta que además del desaliento político de los redactores de La Bandera Nacional, también incidió mucho para su desaparición que el periódico se vendía muy poco, lo que le ocasionaba a los redactares pérdida de tiempo y dinero. Y "viendo esto los redactares de El Argos [...] que sostenían a la administración Márquez y contestaban los ataques de los periódicos de la oposición, cesaron también" $"$.

En el comunicado de despedida de El Argos, publicado en la edición No. 78, del 19 de mayo de 1839, celebraban que sus esfuerzos de defensa del gobierno y del orden constitucional durante cerca de dos años no habían sido infructuosos, denotando el alto valor de su gesta publicitaria en pos de la "restauración" de la política, y a pesar de la gran cantidad de ataques e improperios recibidos por parte de sus antagonistas ${ }^{47}$.

Y en la medida que se recrudecía la situación de inestabilidad del Gobierno, en plena Guerra de los Supremos, a partir de 1839 los miembros del partido de oposición fueron puestos presos con el fin de mandarlos a callar y evitar que asonaran a la opinión pública en contra del gobierno ${ }^{48}$.

${ }^{46}$ Restrepo, Historia de la Nueva Granada... 144.

47 continuación, citamos alguno de los principales apartes de dicho comunicado: “...Vamos, pues, a poner término por ahora a nuestra carrera de escritores públicos: la emprendimos sin odios, sin prevenciones ni pretensiones personales, impulsados solo por un sentimiento puro de patriotismo: la dejamos sin rencores y sin arrepentimiento, con la dulce convicción de que no han sido del todo infructuosos nuestros esfuerzos sinceros en beneficio del país. Durante la lid sostenida con nuestros adversarios en polémica, nos hemos visto tratados con injusticia unas veces, con destemplanza otras, y casi siempre con virulencia y acrimonia: preparados estábamos para ataques de esta especie, y resueltos a oponerles hechos y razones, calma en el debate, e indiferencia absoluta por las frases mordicantes que nos dijeran. Cuando la gran mayoría nacional, la voluntad omnipotente del pueblo, se propuso asegurar el complemento y el triunfo del sistema republicano elevando a la silla presidencial a un ciudadano particular, fuimos también nosotros del número de aquellos que creyeron que había llegado el tiempo de saber si las instituciones juradas eran una realidad o una apariencia vana, y si era o no posible, en el estado actual de civilización y sociabilidad en la Nueva Granada, que su administración marchase tranquila y regularmente por el camino intermedio entre el despotismo y la anarquía bajo los auspicios del poder civil. Combatido desde antes de haber ocupado el solio del poder, por una oposición tenaz y antipática (...) vimos agitarse y desencadenarse las pasiones en el seno de una sociedad naciente, y nos pareció escuchar a lo lejos el bramido de los huracanes que anunciaban una próxima tormenta. Como muchos otros granadinos, nos propusimos entonces conjurarla, o participar de sus estragos a campo descubierto. Entre tantos, éramos desde luego los menos hábiles, pero hemos sido al fin los más perseverantes: y si nuestros adversarios no hubiesen depuesto las armas, por necesidad o por convencimiento, gustosos continuaríamos disputándoles el terreno palmo a palmo. Tocamos retirada cuando ya no hay enemigos con quien combatir...Si acaso, contra nuestras intenciones sin duda, hemos contribuido en algo a la desmoralización de la prensa periódica, si este instrumento útil de los pueblos civilizados y del hombre libre se convirtió en nuestras manos en un arma emponzoñada y traidora; (...) si, en fin, hemos comprometido imprudentemente los intereses grandiosos de la libertad racional, o hemos propalado máximas disolventes dando ansa (sic), de persecución y de retroceso, justo será que nos resulte adverso el fallo del rígido tribunal de la opinión pública ante el cual espontáneamente comparecimos. Pero lo aguardamos tranquilos, confiados en el testimonio de nuestra conciencia y en la rectitud de nuestros propósitos. Nada pierde el país con que en pos de la Bandera Nacional desaparezca el Argos, establecido para contrarrestarla. Resuelto ya favorable y definitivamente el gran problema que por dos años ha estado examinándose, a saber, si era todavía posible que a la voluntad nacionalmente legalmente expresada se sobrepusieran voluntades o pretensiones individuales, como en épocas anteriores de recordación infausta, cualesquiera otras cuestiones son de un interés secundario o pasajero...

${ }^{48}$ Cito en extenso a Restrepo, Historia de la Nueva Granada...198-199., quien describió detalladamente la situación: "Sabíase desde tiempo atrás la existencia en Bogotá de un Club Liberal en que se acordaban las medidas para generalizar la revolución en toda la Nueva Granada. Ordinariamente se tenían las juntas, según la creencia más común, en la casa del doctor Domingo Ciprián Cuenca. A ellos concurrían los doctores Vicente Azuero, Francisco Soto, Florentino González, Salvador Camacho, el General Mantilla y otros varios, la flor y 
Otro acontecimiento funesto para el grupo opositor, que afectó profundamente los ánimos de este grupo, fue la muerte del general Santander, el 6 de mayo de 1840, tras una penosa enfermedad que lo había aquejado durante los últimos años. Con su muerte se marcó el fin del movimiento de oposición que hemos estudiado en el presente trabajo.

Vendrían las elecciones del año 1841, en plena Guerra de los Supremos. A comienzos de dicho año, el juez letrado de hacienda doctor Nicolás Quevedo, ordenó poner en libertad a los opositores del gobierno que estaban presos, lo que le permitió a Azuero postularse nuevamente para el cargo de presidente. Pero de nuevo, el candidato del gobierno, el general Pedro A. Herrán, salió victorioso por encima del antiguo líder opositor.

La oposición liberal quedó reducida al ostracismo y solo resucitaría con un nuevo vigor a partir del año de 1850, en el que se pondrían en marcha las primeras reformas liberales radicales de medio siglo. Pero como señalara Manuel María Madiedo, esta "secta liberal radical", acumuló en su seno, durante doce años de represión -de 1837 a 1849- "los gérmenes de una explosión parecida a la venganza. El partido liberal salió de su tumba como un fantasma lleno de rabia y cubierto de cicatrices"49.

nata del partido liberal. El supremo González contaba con los avisos, noticias y auxilios de estos sus amigos y directores en el plan de derrocar al Gobierno constitucional, y de asumir ellos el poder público. Era por consiguiente necesario frustrar sus designios quitando a los corifeos la facultad de dañar, privándoles por algún tiempo de su libertad, de la que hacían tamaño abuso contra los derechos y garantías de sus conciudadanos. Se les mandó pues, a reducir a una prisión decente donde se les pudiera custodiar e impedir toda comunicación con el enemigo. Azuero, González, Mantilla, Rafael Mendoza y otros fueron encerrados (en las aulas de la Universidad Nacional); Soto y algunos más se ocultaron, aunque no pudieron permanecer escondidos porque todos los ciudadanos se hicieron un deber de buscarlos y descubrirlos. [...] Esta providencia arrancó amargas quejas a los pacientes, que la tacharon de injusta e ilegal. Es cierto que no se fundaba en la ley escrita, pero sí en las leyes eternas de la naturaleza que permiten la defensa, aun matando al enemigo que nos ataque injusta e ilegalmente, como por desgracia y deshonor suyo hacía entonces el partido liberal. Habría sido una verdadera imbecilidad del Gobierno granadino, si en tan apuradas circunstancias hubiera cruzado los brazos, esperando a que sus enemigos [...] le echaran la coyunda al cuello, por no atreverse a romper algunas ligaduras que impedían su acción para salvar la república. La culpa emanaba de la constitución, cuyas reglas solo eran exequibles en tiempos ordinarios, pero no en las revueltas políticas. En estas se presentaba el penoso dilema, de caer el Gobierno nacional, o violar aquellas reglas corriendo transitoriamente un velo sobre la estatua de la libertad." La cita es bastante diciente y muestra cómo, desde recién iniciada nuestra vida republicana, se dejó la puerta abierta a los estados de excepción, con el fin de recuperar la soberanía, o de impedir, por los medios que fuera, cualquier atisbo de anarquía interna.

49 Manuel María Madiedo, Ideas fundamentales de los partidos políticos de la Nueva Granada (Bogotá: Editorial Incunables, 1985), 24. 


\section{Bibliografía}

Arboleda, Gustavo. Historia contemporánea de Colombia (Tomo 2). Bogotá: Banco Central Hipotecario, 1990.

González, Fernán. Para leer la política. Ensayos de Historia Política Colombiana, (2 Tomos). Bogotá: CINEP, 1997.

Guerra, François-Xavier. "El soberano y su reino. Reflexiones sobre la génesis del ciudadano en América Latina”. En Ciudadanía política y formación de las naciones. Perspectivas históricas de América Latina, coordinado por Hilda Sabato, 33-61. México: Fondo de Cultura Económica, 1997.

Lleras, Alberto. Mi gente (Volumen I). Bogotá: Alberto Lleras@, 1976.

Madiedo, Manuel María. Ideas fundamentales de los partidos políticos de la Nueva Granada. Bogotá: Editorial Incunables, 1985.

Obando, José María. Apuntamientos para la historia. Medellín: Editorial Bedout, 1978.

Restrepo, José Manuel. Historia de la Nueva Granada 1832-1845 (Tomo I). Bogotá: Editorial Cromos, 1952.

Safford, Frank. "Formación de los partidos políticos durante la primera mitad del siglo XIX". En Aspectos polémicos de la Historia Colombiana del siglo XIX: Memorias de un Seminario, 9-50. Bogotá: Fondo Cultural Cafetero, 1983.

Santander, Francisco de Paula. Administraciones de Santander, 1834-1835 (Tomo IV). Bogotá: Fundación Francisco de Paula Santander, 1990. 